\title{
In vitro profiling of endocrine disrupting effects of phenols
}

\author{
Jian Li, Mei Ma, Zijian Wang* \\ State Key Laboratory of Environmental Aquatic Chemistry, Research Center for Eco-Environmental Sciences, Chinese Academy of Sciences, P.0. Box 2871, Beijing 100085, China
}

\section{A R T I C L E I N F O}

\section{Article history:}

Received 3 April 2009

Accepted 11 September 2009

Available online 16 September 2009

\section{Keyword:}

Phenols, Estrogen receptor

Androgen receptor

Progesterone receptor

Estrogen-related receptor

Yeast two-hybrid assay

\begin{abstract}
A B S T R A C T
Some phenols have been suspected to modulate the endocrine systems of wildlife and humans, but less is known about their interactions with different types of nuclear receptors. In this study, the ability of 2tert-butylphenol, 2-isopropylphenol, 4-tert-octylphenol (4-t-OP), 2,4-dichlorophenol (2,4-DCP), 3,4dichlorophenol (3,4-DCP), pentachlorophenol (PCP), bisphenols A (BPA), tetrabromobisphenol A (TBBPA), tetrachlorobisphenol A (TCBPA) and 4-phenylphenol to activate estrogen receptor (ER), androgen receptor (AR), progesterone receptor (PR) and estrogen-related receptor (ERR) were determined using a set of recombined yeast strains. It was found that 4-t-OP, 3,4-DCP, PCP, BPA, TBBPA, TCBPA and 4-phenylphenol were ER $\alpha$ agonists, while 4-t-OP, PCP and 4-phenylphenol showed ER $\alpha$ antagonistic activities. 2-tertButylphenol, 4-t-OP, 2-isopropylphenol, 2,4-DCP, 3,4-DCP, BPA, TCBPA and 4-phenylphenol were antagonists for AR, whereas none of the compounds studied were found to be an AR agonist. TCBPA, TBBPA and PCP were PR antagonists, and 2-tert-butylphenol, 3,4-DCP, 4-t-OP, 4-phenylphenol and 2-isopropylphenol were weak inhibitors on expression under control of the PR. None of the phenols were PR agonists. 2-tert-Butylphenol, 4-t-OP and PCP were ERR $\gamma$ inverse agonists, while 2,4-DCP, 3,4-DCP, PCP, BPA, TBBPA and TCBPA exhibited the ability to reverse the ERR inhibition induced by 4-hydroxytamoxifen. Based on the functional agonistic or antagonistic receptor-mediated effects, we further discussed the possible action mechanisms of these phenols as endocrine disrupting chemicals.
\end{abstract}

() 2009 Elsevier Ltd. All rights reserved.

\section{Introduction}

Over the past 20 years there has been increasing concern by both the public and researchers that phenols and many other related environmental chemicals have the ability to modulate the neuro-endocrine system and thus adversely affect human and wildlife reproduction (Terasaka et al., 2006). Several possible mechanisms of action, including direct hormone agonists or antagonists that could mimic or inhibiting endogenous hormone action, by modulating the production of endogenous hormones, or by altering hormone receptor have been suggested (Sonnenschein and Soto, 1998). Thus, hormone receptors have become one of the subjects of research on endocrine disruptors in general, but most of the research has focused primarily on estrogen receptor (ER) agonists. However, the endocrine system is more complex and presents a large number of potential endocrine disrupting chemical (EDC) target sites (Kristensen et al., 2006). Thus, to accurately predict the potential effects of mixtures of endocrine disruptors, it is important to study the interaction of EDCs with different types of hormone receptors and through indirect mechanisms of effect.

\footnotetext{
* Corresponding author. Tel./fax: +86 1062849140.

E-mail address: wangzj@rcees.ac.cn (Z. Wang).
}

The steroid receptors, including the ER, androgen receptor (AR) and progesterone receptor (PR) are classified as members of the subfamily within the nuclear receptor super-family 3 (Nuclear Receptors Nomenclature Committee, 1999). It is well known that androgens are important physiologically in male mammals, which stimulates or controls the development and maintenance of masculine characteristics by binding to AR (Meisel and Sachs, 1994). Recent studies have shown that several chemicals may exert anti-androgenic effect by interfering with AR (Sohoni and Sumpter, 1998). For example, $p, p^{\prime}$-dichlorodiphenylethane ( $p, p^{\prime}$-DDE), bisphenol A (BPA), octylphenol (OP) and nonylphenol (NP) have demonstrated in vitro AR-mediated anti-androgenic activities (Xu et al., 2005). Besides estrogens and androgens, progesterone is also a key regulator of proliferation and differentiation in reproductive tissues (Graham and Clarke, 1997). The effects of progesterone are mediated via the PR. Several pieces of evidence indicate that some synthetic chemicals in the environment are able to inhibit the binding of the progesterone to PR (Wang et al., 2005). But only a limited number of environmental chemicals with anti-progesterone-like properties have been identified (Klotz et al., 1997), while little information is available on progesterone-like or anti-progesterone activity and on the relationship between estrogenic, androgenic and progesterone activity in the environmental chemicals (Wang et al., 2005). 
Table 1

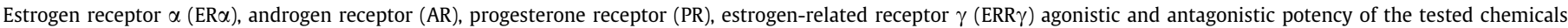

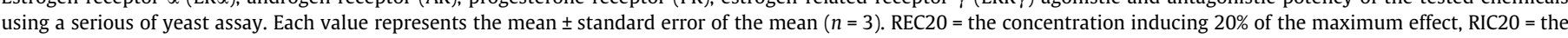
concentration reducing $20 \%$ of the maximum effect, RC20 = the concentration reversing $20 \%$ of the inhibition by 4 -hydroxytamoxifen. ${ }^{\text {. }}$.

\begin{tabular}{|c|c|c|c|c|c|c|c|c|}
\hline & \multicolumn{2}{|l|}{$\mathrm{ER} \alpha$} & \multicolumn{2}{|l|}{ AR } & \multicolumn{2}{|l|}{ PR } & \multicolumn{2}{|l|}{$\mathrm{ERR} \gamma$} \\
\hline & $\operatorname{REC} 20(\mathrm{~mol} / \mathrm{L})$ & RIC20 (mol/L) & $\mathrm{REC} 20(\mathrm{~mol} / \mathrm{L})$ & RIC20 (mol/L) & $\operatorname{REC} 20(\mathrm{~mol} / \mathrm{L})$ & $\operatorname{RIC} 20(\mathrm{~mol} / \mathrm{L})$ & $\mathrm{RC} 20$ (mol/L) & RIC20 (mol/L) \\
\hline \multicolumn{9}{|l|}{ Alkylphenols } \\
\hline 2-tert-butylphenol & ND & ND & ND & $1.1 \mathrm{E}-05$ & ND & $1.5 \mathrm{E}-06$ & ND & $>1.0 \mathrm{E}-04$ \\
\hline $4-t-O P$ & $2.1 \mathrm{E}-7$ & $6.6 \mathrm{E}-6$ & ND & $1.6 \mathrm{E}-06$ & ND & $1.2 \mathrm{E}-06$ & ND & $3.5 \mathrm{E}-06$ \\
\hline 2-Isopropylphenol & ND & ND & ND & $1.6 \mathrm{E}-06$ & ND & $1.8 \mathrm{E}-05$ & ND & ND \\
\hline \multicolumn{9}{|l|}{ Chlorinated phenols } \\
\hline $2,4-\mathrm{DCP}$ & ND & ND & ND & $1.0 \mathrm{E}-05$ & ND & ND & $1.0 \mathrm{E}-04$ & ND \\
\hline 3,4-DCP & $1.0 \mathrm{E}-4$ & ND & ND & $1.3 \mathrm{E}-05$ & ND & $2.4 \mathrm{E}-06$ & $>1.0 \mathrm{E}-04$ & ND \\
\hline РCP & $>1.0 \mathrm{E}-5$ & $6.2 \mathrm{E}-7$ & ND & ND & ND & $7.6 \mathrm{E}-07$ & $1.0 \mathrm{E}-05$ & $3.0 \mathrm{E}-06$ \\
\hline \multicolumn{9}{|l|}{ Bisphenols } \\
\hline BPA & $1.0 \mathrm{E}-5$ & ND & ND & $1.2 \mathrm{E}-06$ & ND & ND & $1.0 \mathrm{E}-04$ & ND \\
\hline TBBPA & $>1.0 \mathrm{E}-5$ & ND & ND & ND & ND & $7.8 \mathrm{E}-08$ & $>1.0 \mathrm{E}-06$ & ND \\
\hline TCBPA & $>1.0 \mathrm{E}-5$ & ND & ND & $1.0 \mathrm{E}-05$ & ND & $2.7 \mathrm{E}-08$ & $>1.0 \mathrm{E}-06$ & ND \\
\hline \multicolumn{9}{|l|}{ Phenylphenol } \\
\hline
\end{tabular}

a $n \geqslant 3$; ND: no detection.

Because no endogenous ligands have been identified for estrogen-related receptors (ERRs), they are classified as a subfamily of orphan nuclear receptors closely related to ER $\alpha$ and ER $\beta$ (Horard and Vanacker, 2003). ERRs and ERs have a high degree of amino acid sequence similarity and identity in both their DNA-binding (DBD) and ligand-binding (LBD) domains. ERRs can bind to functional estrogen response elements (EREs) in ER target genes, suggesting possible similarities between ERR and ER action (Takayanagi et al., 2006). Some synthetic chemicals including BPA, 4-hydroxytamoxifen (4-OHT), diethylstilbestrol, 4-NP, and the endogenous hormone, estrone have been reported to be able to bind to human ERR $\gamma$ (Takayanagi et al., 2006).

Regarding various EDCs, many phenols suspected as xenoestrogens, such as NP, OP and BPA, are a constant concern from the environmental point of view due to their large distribution. For example, aquatic biology can be exposed to these phenols not only because of the discharge from industrial and municipal wastewater treatment plant effluents, but also due to direct discharge (Suzuki et al., 2004). The endocrine disruption effects of these chemicals have been reported, for example, 4- $t$-OP, BPA, 2,4dichlorophenol (2,4-DCP) have been long acknowledged to be estrogenic chemicals having the ability to interact with human ER (Nishihara et al., 2000). However, less is known about the interaction of these phenols with other nuclear receptors such as AR, PR or ERR. Based on different structures and different types (e.g. alkylphenols, chlorinated phenols, bisphenols and phenylphenols), 10 phenolic compounds were selected (listed in Table 1). This study was conducted to determine the effects of these specific phenols on nuclear receptors. For this purpose, the recombinant yeast assays were carried out to investigate the effects of phenols (listed in Table 1) on ER, AR, PR and ERR-mediated transcription of $\beta$ galactosidase in vitro in reporter yeasts. These test systems could be used for the rapid, high-throughput screening of chemicals for their agonist and antagonist properties for ER, AR, PR and ERR.

\section{Materials and methods}

\subsection{Chemicals}

$17 \beta$-Estradiol(E2, 97\%, CAS No. 50-28-2), dimethyl sulfoxide (DMSO, 99.5\%, CAS No. 67-68-5), BPA (99\%, CAS No. 80-05-7), 4$t$-OP (97\%, CAS No. 140-66-9), pentachlorophenol (PCP, 99\%, CAS No. 87-86-5) and 4-OHT (98\%, CAS No. 68047-06-3) were pur- chased from Sigma Chemical (St. Louis, MO, USA). 2-tert-Butylphenol (99\%, CAS No. 88-18-6), 2-isopropylphenol (97\%, CAS No. 8869-7), tetrabromobisphenol A (TBBPA, 97\%, CAS No. 79-94-7), 2,4-DCP (99\%, CAS No. 120-83-2), 3,4-dichlorophenol (3,4-DCP, 99\%, CAS No. 95-77-2) and 4-phenylphenol (97\%, CAS No. 92-693) were purchased from Acros Organics (Geel, Belgium). Dihydrotestosteron (DHT, CAS No. 521-18-6) and tetrachlorobisphenol A (TCBPA, CAS No. 79-95-8) were obtained from Tokyo Chemical Industry (Osaka, Japan). Progesterone (CAS No. 57-83-0) was purchased from the MP Biomedical, Eschwege, Germany. For all compounds, stock solutions were prepared in DMSO. Final chemical concentration in the DMSO stock was $0.2 \mathrm{~mol} / \mathrm{L}$.

\subsection{Yeast strain}

Yeast strains respectively transformed with the ER $\alpha$ gene, ERR $\gamma$ gene or AR gene were constructed in our laboratory using yeast two-hybrid assay system and selected by growth on synthetic dextrose (SD) medium (lacking tryptophan and leucine, SD/-Leu/-Trp) according to the method described in our previous paper ( $\mathrm{Li}$ et al., 2008a,b). Briefly, we introduced two expression plasmids, bait plasmid and hunter plasmid, into yeast cells.

Another yeast strain transformed with the PR gene was a kind gift of Dr. Kevin W. Gaido (Chemical Industry Institute of Toxicology, Research Triangle Park, North Carolina, USA). Yeast (Saccharomyces cerevisiae) stably transfected with the human PR gene and expression plasmids carrying a progesterone response element, while the reporter LacZ gene encoding the enzyme $\beta$-galactosidase was used. The yeast strain was grown in synthetic complete (SC) medium with tryptophane, but lacking histidine and leucine (SC/-His/-Leu) following the prescription of Gaido et al. (1997).

The ER $\alpha, A R$, PR and ERR $\gamma$ yeast used in this study had been detected, in our previous study, to have high ability of interacting with known agonists and antagonists (Table 2), thus high sensitivity for screen chemicals with ant/agonistic activity (Li et al., 2008a,b).

\section{3. $\beta$-Galactosidase assay}

The yeast assay was conducted as described by Ma et al. (2005). Yeast strains were grown overnight at $30^{\circ} \mathrm{C}, 130 \mathrm{rpm}$ with vigorous shaking. Each test chemical was serially diluted in DMSO. Five microliters of serial dilutions of test samples were combined with 
Table 2

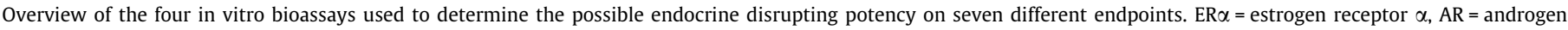

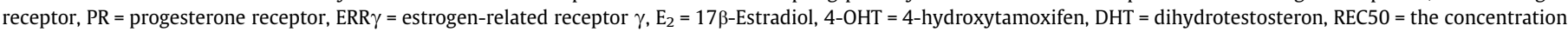
inducing $50 \%$ of the maximum effect, RIC50 = the concentration causing a 50\% inhibition of the maximum effect.

\begin{tabular}{|c|c|c|c|}
\hline Bioassay & Reference material & Endpoint & REC50 or RIC50 (mol/L) \\
\hline Two-hybrid ER $\alpha$-Laz & $\begin{array}{l}\mathrm{E}_{2} \\
4-\mathrm{OHT}\end{array}$ & $\begin{array}{l}\text { Estrogenic activity through } \mathrm{ER} \alpha \\
\text { Antiestrogenic activity through } \mathrm{ER} \alpha \text { in the presence of } \mathrm{E}_{2}\end{array}$ & $\begin{array}{l}2.5 \times 10^{-10 a} \\
1.2 \times 10^{-6 a}\end{array}$ \\
\hline Two-hybrid AR-Laz & $\begin{array}{l}\text { DHT } \\
\text { Flutamide }\end{array}$ & $\begin{array}{l}\text { Androgenic activity through AR } \\
\text { Anti-androgenic activity through AR in the presence of DHT }\end{array}$ & $\begin{array}{l}1.3 \times 10^{-8 b} \\
9.8 \times 10^{-6 b}\end{array}$ \\
\hline PR-Laz & $\begin{array}{l}\text { Progesterone } \\
\text { RU486 }\end{array}$ & $\begin{array}{l}\text { Progestagenic activity through PR } \\
\text { Antiprogestagenic activity through PR in the presence of progesterone }\end{array}$ & $\begin{array}{l}5 \times 10^{-10 b} \\
6.6 \times 10^{-6 b}\end{array}$ \\
\hline Two-hybrid ERR $\gamma$-Laz & 4-OHT & Inhibition of the constitutive activity through ERR $\gamma$ & $7.9 \times 10^{-6 b}$ \\
\hline
\end{tabular}

a According to Li et al. (2008a).

b According to Li et al. (2008b).

$995 \mu \mathrm{L}$ of medium containing $5 \times 10^{3}$ yeast cells $/ \mathrm{mL}$ resulting in a test culture. Two hundred microliters of the test cultures were transferred into each well of the 96-well plate and incubated at $30{ }^{\circ} \mathrm{C}$ with vigorous orbital shaking ( $800 \mathrm{rpm}$ ) for $2 \mathrm{~h}$, then the cell density of the culture was measured at $600-\mathrm{nm}$ wavelength (TECAN GENios A-5002, Salzburg, Austria).

A $50 \mu \mathrm{L}$ test culture was transferred to a new 96-well plate and after addition of $120 \mu \mathrm{L}$ of Z-buffer $\left(16.1 \mathrm{~g} / \mathrm{L} \mathrm{Na}_{2} \mathrm{HPO}_{4} \cdot 7 \mathrm{H}_{2} \mathrm{O} ; 5.5 \mathrm{~g} /\right.$ $\left.\mathrm{L} \mathrm{NaH} \mathrm{PO}_{4} \cdot \mathrm{H}_{2} \mathrm{O} ; 0.75 \mathrm{~g} / \mathrm{L} \mathrm{KCl} ; 0.246 \mathrm{~g} / \mathrm{L} \mathrm{MgSO}_{4} \cdot 7 \mathrm{H}_{2} \mathrm{O}\right)$ and $20 \mu \mathrm{L}$ chloroform, the assays were carefully mixed (vortex $25 \mathrm{~s}$ ). The enzyme reaction was initiated by addition of $40 \mu \mathrm{L} o$-nitrophenyl- $\beta$ D-galactopyranoside ( $13.3 \mathrm{mmol} / \mathrm{L}$, dissolved in Z-buffer) and incubated at $30^{\circ} \mathrm{C}$ for $60 \mathrm{~min}$. The reactions were terminated by the addition of $100 \mu \mathrm{L} \mathrm{Na} \mathrm{CO}_{3}(1 \mathrm{~mol} / \mathrm{L})$. After centrifugation at $12,000 \mathrm{~g}$ for $15 \mathrm{~min}$ (Sigma Laborzentrifugen $2 \mathrm{~K} 15$, Osterode, Germany), $200 \mu \mathrm{L}$ of the supernatant was transferred into a new 96well plate and the absorbance at $420 \mathrm{~nm}$ was determined. The $\beta$ galactosidase activity was calculated according to reports by Ma et al. (2005), $\beta$-galactosidase activities are expressed as the means and standard deviations of the results from three independent transformed yeast clones and for each clone, all samples were evaluated in triplicate. The antagonistic activity of samples was tested by co-incubation of yeast strain with nature ligand which produced a sub-maximal stimulatory response $\left(2 \times 10^{-10} \mathrm{~mol} / \mathrm{L} \mathrm{E}_{2}\right.$, $5 \times 10^{-8} \mathrm{~mol} / \mathrm{L}$ DHT and $1 \times 10^{-9} \mathrm{~mol} / \mathrm{L}$ progesterone, respectively; Li et al., 2008).

To ensure that increased/reduced activities in the bioassay were caused by true agonistic/antagonistic responses but not by cytotoxicity, viability was measured. After exposure, cell viability was determined spectrophotometrically as a change of cell density $\left(\mathrm{OD}_{600 \mathrm{~nm}}\right)$ in the assay medium.

\subsection{Data analysis}

For some compounds yielding responses lower than $50 \%$ of the positive control value, the concentration inducing $50 \%$ of the maximum effect (REC50) or the concentration causing a $50 \%$ of the maximum effect (RIC50) was not calculated. Then, the concentration resulting in $20 \%$ of the maximum effect (REC20) or the concentration reducing $20 \%$ of the maximum effect (RIC20, inducing $80 \%$ of the maximum effect) was calculated for test compounds. The RC20 value, which means the concentration reversing $20 \%$ of the inhibition by 4-OHT, was specifically used for evaluation the compounds with reversing ERR $\gamma$ activities. For compounds yielding responses less than $20 \%$ of the positive control value, but showing a significant difference from the negative control, the REC20 or RIC20 values were greater than the minimum value (>minimum value) having significant difference (Table 1 ). The dose-response curve was generated using a four-parameter logistic model based on the Marquardt-Levenberg algorithm (Sigmaplot 4.0, SPSS, Chicago,
IL, USA) (Rehmann et al., 1999).The four-parameter logistic equation gives a dose response curve fitted to the measured values REC20 as well as the opportunity to calculate RIC20 values for antagonistic assays.

\section{Result and discussion}

\subsection{Gene expression modulation via the ER $\alpha$}

To study ER agonistic activity, two-hybrid ER $\alpha$ yeast was tested in the presence of increasing concentrations $\left(1 \times 10^{-9}\right.$ $1 \times 10^{-4} \mathrm{~mol} / \mathrm{L}$ ) of phenolic endocrine disrupting compounds. 4$t$-OP, 3,4-DCP, BPA and 4-phenylphenol was found to be ER $\alpha$ agonists that significantly induced expression of a reporter, $\beta$-galactosidase, in a dose-dependent manner (Fig. 1A). The REC20 value of 4-t-OP, 3,4-DCP, BPA and 4-phenylphenol were $2.1 \times 10^{-7}$, $1.0 \times 10^{-4}, 1.0 \times 10^{-5}$ and $2.4 \times 10^{-6} \mathrm{~mol} / \mathrm{L}$. PCP, TBBPA and TCBPA' only showed ER $\alpha$-binding activity at the highest concentration without cytotoxicity. The REC20 value of these compounds could not be calculated and these compounds could not be included in Fig. 1A.

When the test chemicals were co-administered with $2 \times$ $10^{-10} \mathrm{~mol} / \mathrm{L}$ of $E_{2}$, some of them suppressed the $\beta$-galactosidase activity (Fig. 1B). The inhibition by 4-t-OP, PCP and 4-phenylphenol demonstrated a dose-effect relationship. The RIC20 value of 4-tOP, PCP and 4-phenylphenol were $6.6 \times 10^{-6}, 6.2 \times 10^{-7}$ and $3.1 \times 10^{-7} \mathrm{~mol} / \mathrm{L}$.

The test chemicals were also demonstrated that they did not affect the viability and proliferation of yeast cell, alone or with $2 \times 10^{-10} \mathrm{~mol} / \mathrm{L} \mathrm{E}_{2}$ assay (data not shown). This indicates that no cytotoxic effect existed in the tested concentration range.

Recently, Nishihara et al. (2000) used a yeast two-hybrid assay system to test 517 chemicals including 4-t-OP, 3,4-DCP, BPA, PCP, TBBPA and TCBPA as potential agonists to the rat ER, which were similar to our result. Moreover, in the present study, 4-phenylphenol induced the activity of human ER $\alpha$ when its concentration increased to $10^{-7} \mathrm{~mol} / \mathrm{L}$, which was consistence with the report by Dhooge et al. (2006) also using a yeast assay.

The data shown here suggests that 4-t-OP, PCP and 4-phenylphenol were able to interact with significant affinity with ER $\alpha$ showing antagonistic activity. Whereas few results concerning antiestrogenic activity of these chemicals have been reported previously, Jung et al. (2004) proposed that PCP may be antiestrogenic rather than estrogenic when tested by in vitro assays including the yeast two-hybrid assay, MCF-7 cells and ER competitive binding assay, which supports our results. This study revealed that 4-tOP, PCP and 4-phenylphenol showed inhibition of estrogenic activity and these compounds also showed agonistic activity (Table 1), suggesting the antiestrogenic activity upon binding to ER. In addition, Soto et al. (1997) tested the estrogenicity of some 

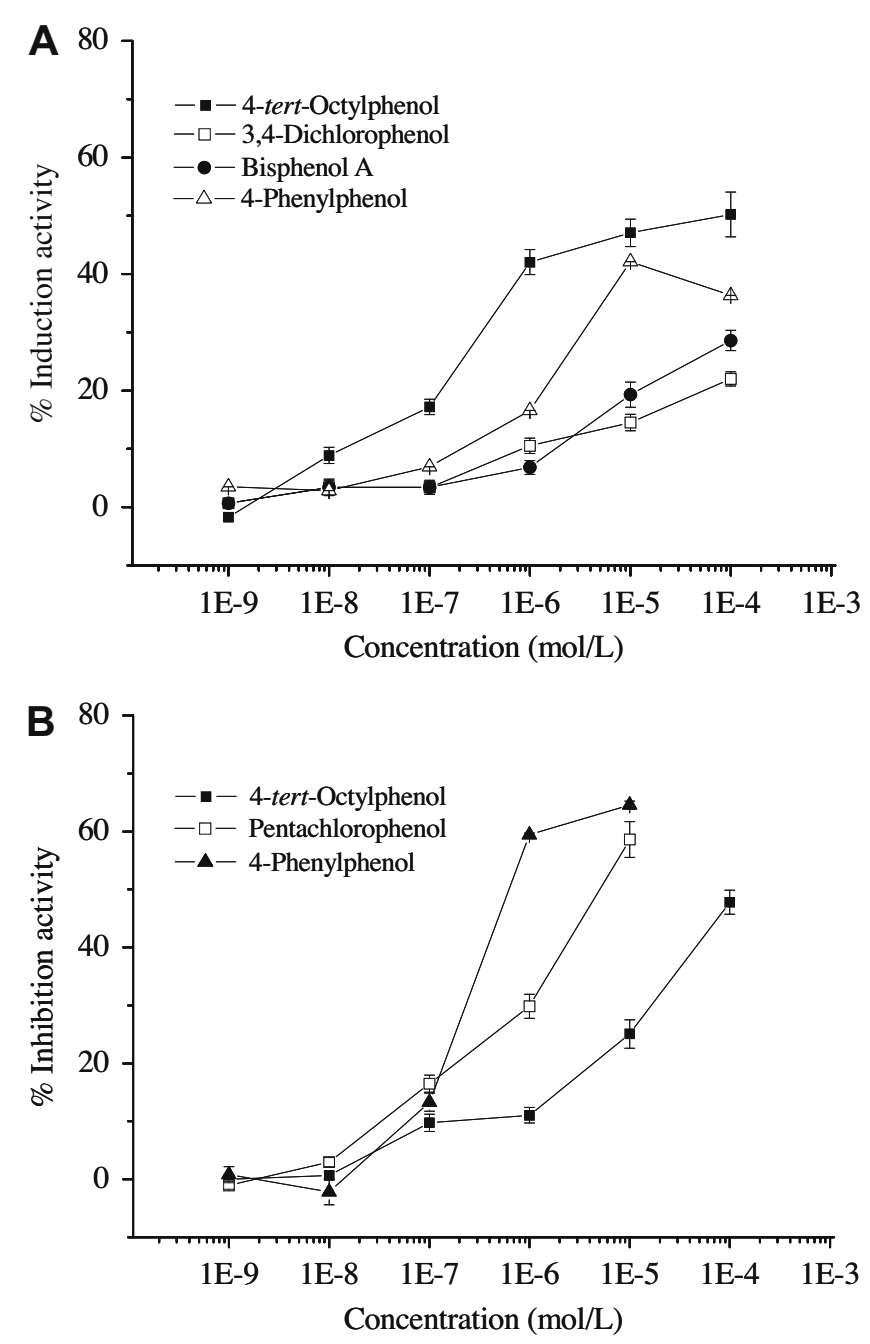

Fig. 1. (A) Estrogen receptor $\alpha(E R \alpha)$ agonistic activity of test chemicals determined by the yeast strain ER $\alpha$-GRIP1. (B) ER $\alpha$ antagonistic activity of test chemicals determined by the yeast strain ER $\alpha$-GRIP1. The chemical's ant/agonistic activity is represented as the percent inhibition or induction activity relative to the maximum induced by $17 \beta$-estradiol $\left(\mathrm{E}_{2}, 2 \times 10^{-10} \mathrm{~mol} / \mathrm{L}\right)$. Values are presented as the average \pm standard error $(n=3)$.

xenoestrogens using the E-SCREEN assay, and reported that some full agonists were devoid of antagonistic effects and partial agonists were also partial antagonists.

\subsection{Gene expression modulation via the AR}

Our result showed that none of the test compounds caused any AR tranactivation (data not list). 2-t-Butylphenol, 4-t-OP, 2-isopropylphenol, 2,4-DCP, 3,4-DCP, BPA, TCBPA and 4-phenylphenol were found to be AR antagonists and inhibited the $\beta$-galactosidase activity induced by DHT in a concentration dependent manner (Fig. 2). However, the inhibition effects of PCP and TBBPA were not found. The RIC20 values of test chemicals with antagonistic activity were listed in Table 1. Among these compounds, 4-t-OP, 2-isopropylphenol and BPA were more effective inhibitor, with RIC20 values lower than $1.0 \times 10^{-5} \mathrm{~mol} / \mathrm{L}$ (Table 1 ).

In this study, we found that 2-t-butylphenol, 4-t-OP, 2-isopropylphenol, 2,4-DCP, 3,4-DCP and 4-phenylphenol were anti-androgens. 4-t-OP was also reported to have an inhibitory effect on the androgenic activity of DHT by means of androgen-responsive luciferase reporter gene assay using MDA-kb2 human breast cancer cells (Tamura et al., 2006). For 4-phenylphenol, 4-hydroxyl group has been demonstrated to be effective in phenylphenols to repress AR transcription (Paris et al., 2002). Kitamura et al. (2005) reported isopropylphenol was a potent anti-androgen with $\mathrm{RIC}_{50}$ value of $6.2 \times 10^{-5} \mathrm{~mol} / \mathrm{L}$, which was consistence with our research. In the present study, 2,4-DCP was found to have anti-androgenic activity, which also was supported by the study of Tamura et al. (2006). However, Kim et al.'s (2005) work suggested that 2,4-DCP $\left(1.0 \times 10^{-10} \mathrm{~mol} / \mathrm{L}\right)$ exhibited synergistic androgenic activities by co-treatment with DHT. This result may be due to the different concentration selected for the measurement $\left(1.0 \times 10^{-10} \mathrm{~mol} / \mathrm{L}\right.$ vs. $1.0 \times 10^{-5} \mathrm{~mol} / \mathrm{L}$ ) and suggests that the disturbing effect of 2,4-DCP on AR may be related to the exposure concentration. It has been reported that 3,4-DCP showed estrogenic activity (Table 1), in addition, Sohoni and Sumpter (1998) suggested that many oestrogens possess combining activity to AR. So, we detected the ant/agonistic activity of this compound and found that 3,4-DCP did inhibit AR-mediated reporter that co-treatment with DHT. However, PCP was inactive for AR, suggesting PCP was not an agonist or antagonist of androgen, which was supported by Sun et al. (2006).

In the present study, we found that BPA was not an AR agonist, but was an AR antagonist. In previous studies, BPA has been demonstrated to have AR-mediated anti-androgenic activities using in vitro yeast-based assay (Lee et al., 2003). Sun et al. (2006) also reported that it was failed to find the AR agonistic effect of BPA, but found that BPA was an effective inhibitor of androgen-induced AR transcriptional activity (IC50 value of $2.14 \times 10^{-6} \mathrm{~mol} / \mathrm{L}$ ). The AR antagonistic activities of TCBPA have been investigated while the data contradicted each other. Sun et al. (2006) proved that TCBPA was an anti-androgen (IC50 value of $1.0 \times 10^{-5} \mathrm{~mol} / \mathrm{L}$ ). However, Kitamura et al. (2005) reported that TCBPA was not an androgen antagonist. In our study, TCBPA exhibited weaker antiandrogenic activities (RIC20 of $1.0 \times 10^{-5} \mathrm{~mol} / \mathrm{L}$ ) than did BPA. In addition, the antagonistic effect was not measured for TBBPA, which was consistent with the values reported by Kitamura et al. (2005).

These results suggest that many test compounds including some alkylphenol, chlorophenol, phenylphenol, BPA and BPA derivatives, act as AR antagonists. Once bound to AR, the androgen antagonists are transported into the nucleus and prevent endogenous androgens from regulating androgen-dependent transcription. The AR-compound interaction may be crucial contributor to adverse effects on male reproductive system. For example, exposure of fish to some anti-androgens has been associated with gonadal changes (induction of intersex), reduced spermatogenesis, demasculinization, and reduced sperm counts (Kiparissis et al., 2003).

\subsection{Gene expression modulation via the $P R$}

The potential activity of phenols via PR was investigated using recombined PR yeast, in which none of the above-mentioned compounds showed agonistic activity (data not list). Antagonist activity was determined by co-incubation with $1 \times 10^{-9} \mathrm{~mol} / \mathrm{L}$ progesterone. In the results, TCBPA, TBBPA and PCP showed strong antagonistic effects with the RIC20 value of $2.7 \times 10^{-8}, 7.8 \times 10^{-8}$ and $7.6 \times 10^{-7} \mathrm{~mol} / \mathrm{L}$, respectively (Fig. 3, Table 1 ). At $1.0 \times$ $10^{-6} \mathrm{~mol} / \mathrm{L}$ and greater, 2-t-butylphenol, 3,4-DCP, 4-t-OP, 4-phenylphenol and 2-isopropylphenol decreased the $\beta$-galactosidase expression obviously, then the RIC20 values for these compounds were determined and listed in Table 1 . In contrast, 2,4-DCP and BPA were not antagonists of the PR.

Our results have demonstrated both $4-t-O P$ and PCP to be antagonists. The effect of these compounds on the PR has previously been investigated and it was confirmed that 4-t-OP and PCP inhibited progesterone-induced reporter gene activity in a 


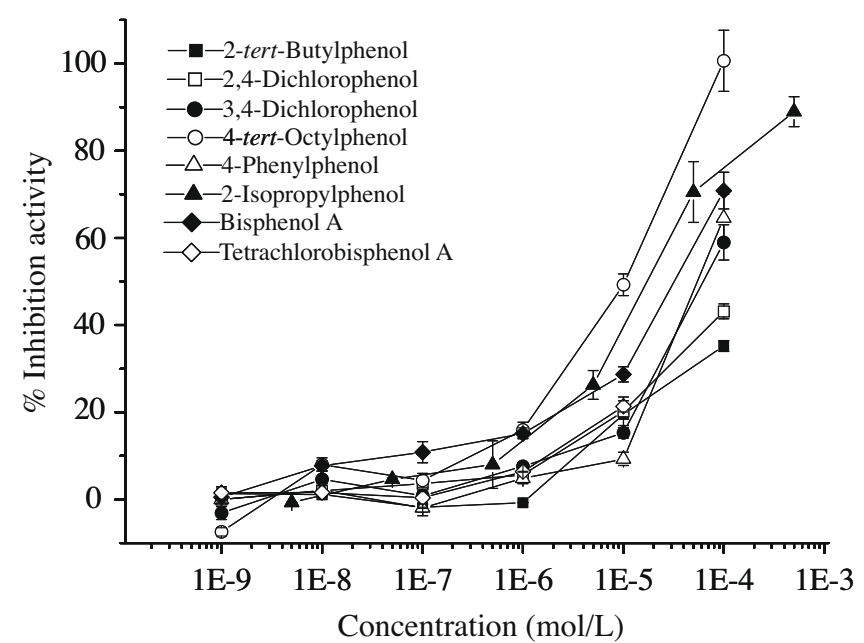

Fig. 2. Typical androgen receptor (AR) antagonistic activity of test chemicals determined by the yeast strain AR-GRIP1. The chemical's antagonistic activity is represented as the percent inhibition activity relative to the maximum induced by dihydrotestosterone (DHT, $5 \times 10^{-8} \mathrm{~mol} / \mathrm{L}$ ). Values are presented as the average \pm standard error $(n=3)$.

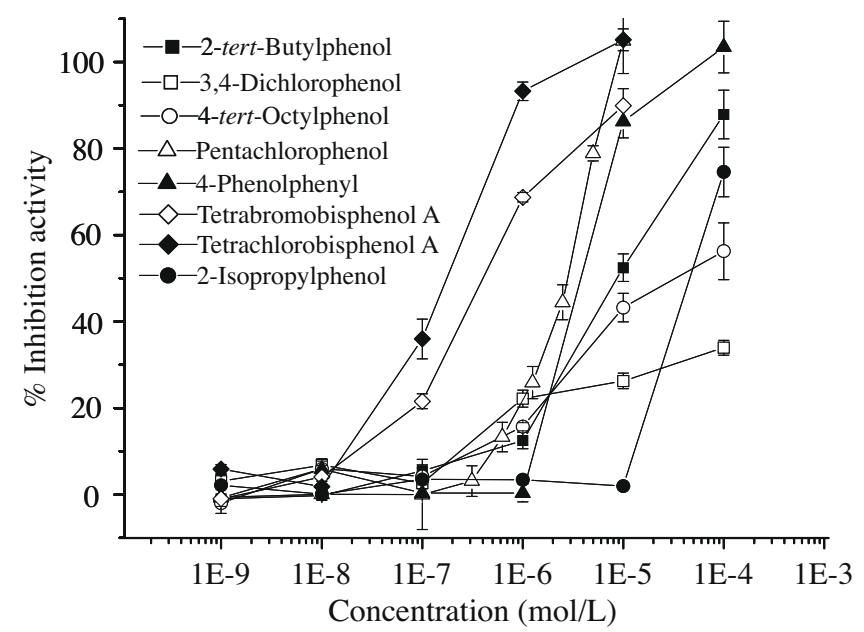

Fig. 3. Typical progesterone receptor (PR) antagonistic activity of test chemicals determined by the yeast strain PR. The chemical's antagonistic activity is represented as the percent inhibition activity relative to the maximum induced by progesterone $\left(1 \times 10^{-9} \mathrm{~mol} / \mathrm{L}\right)$. Values are presented as the average \pm standard error $(n=3)$.

dose-dependent manner with RIC50 value of $2.5 \times 10^{-6}$ and $1.0 \times 10^{-6} \mathrm{~mol} / \mathrm{L}$, respectively (Tran et al., 1996). Tran et al. (1996) also confirmed that 2,4-DCP had not any ant/agonistic activity. But, the fact that 2-t-butylphenol, 3,4-DCP, 4-phenylphenol and 2-isopropylphenol inhibited of PR-controlled $\beta$-galactosidase expression, suggesting that they are PR antagonists, has not been reported previously.

The agonistic or antagonistic effect of BPA had been investigated. The result showed that BPA did not act with PR (Tran et al., 1996), which was confirmed by our research. TBBPA and TCBPA, halogenated derivatives of BPA, have been studied on their action with ER, but there was little work to study their action with PR. Our results have demonstrated both TBBPA and TCBPA to be strong PR antagonists (RIC20 value lower than $1.0 \times 10^{-7} \mathrm{~mol} / \mathrm{L}$ ). The ability of TBBPA and TCBPA to inhibit progesterone-induced gene transcription in the yeast may reflect the ability of these compounds to compete with progesterone for binding to PR.
Although to date, only a limited number of environmental chemicals with anti-progesteronic properties have been identified, the disruption effects, especially the antagonistic effects, of environmental samples (e.g. soot from fossil fuel combustion) have been demonstrated (Wang et al., 2005). Recently other researchers have stressed the importance of some progesterones to fish, in which they act as pheromones crucial for eliciting physiological and behavioral responses in the sex (Sumpter, 2005). In addition, some studies have demonstrated that functional interactions between estrogen and progesterone are fundamental to maintaining some physiological process and suggested that progestins can oppose the effects of estrogens in some systems (Kraus et al., 1995). Thus, research on the agonistic and antagonistic activities of the chemicals provide endocrine disrupting mechanistic insight in the level at which these compounds are likely to disturb the PR system and induce/inhibit PR mediated cellular responses.

\subsection{Modulation gene expression via the ERR $\gamma$}

Our result showed that 4-t-OP and PCP were strong ERR $\gamma$ inverse agonists with RIC20 values of $3.5 \times 10^{-6}$ and $3.0 \times 10^{-6} \mathrm{~mol} / \mathrm{L}$, respectively (Fig. 4A). The inhibition effect of 2-t-butylphenol
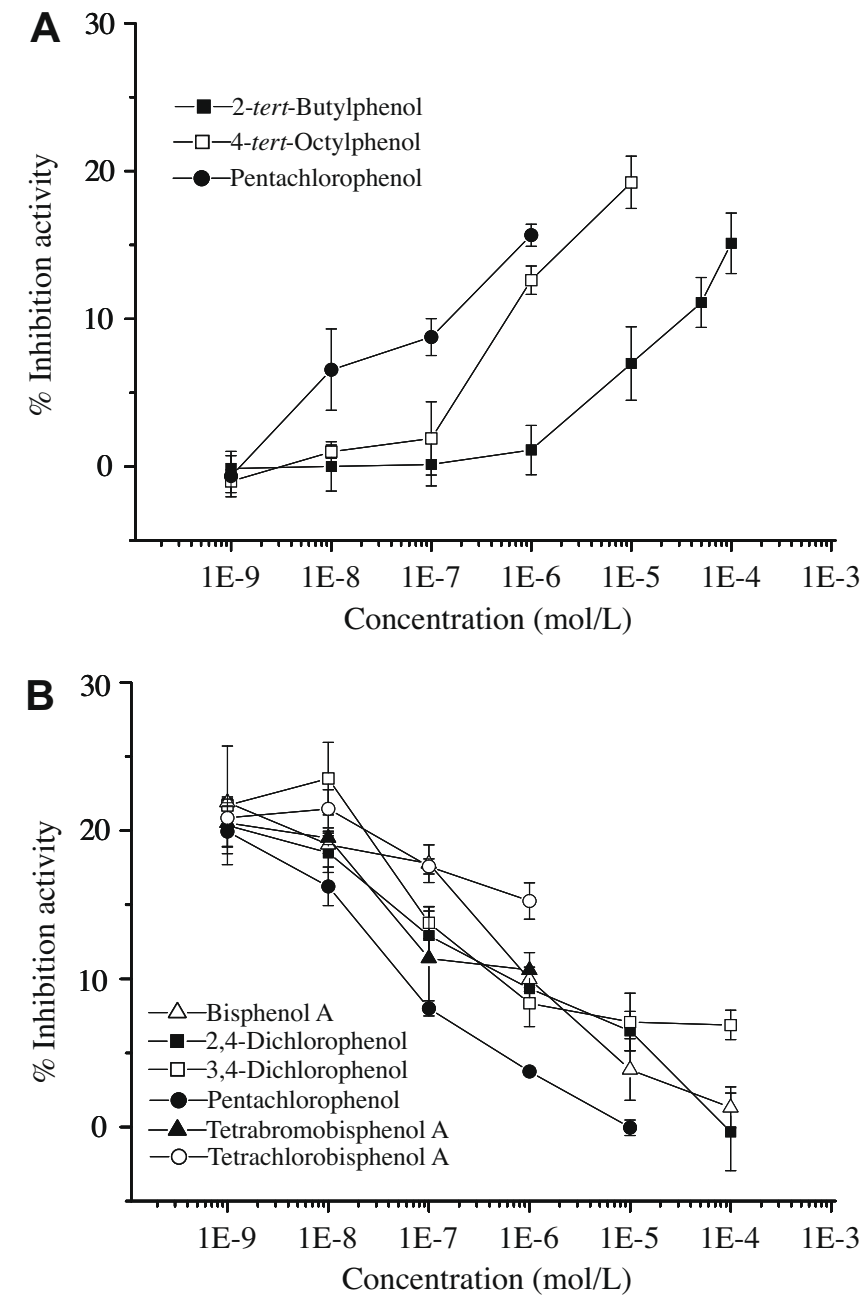

Fig. 4. (A) Typical estrogen-related receptor $\gamma$ (ERR $\gamma$ ) inverse agonistic activity of test chemicals determined by the yeast strain ERR $\gamma$-GRIP1. (B) Effect of test chemicals on the inverse agonist activity of 4-hydroxytamoxifen (4-OHT) in yeast strain ERR $\gamma$-GRIP1.The chemical's inverse agonistic activity is represented as the percent inhibition activity relative to the high constitutive activity in yeast strain ERR $\gamma$-GRIP1. Values are presented as the average \pm standard error $(n=3)$. 
was so weak that the RIC20 value could not be determined (Table 1 ). However, other compounds did not decrease $\beta$-galactosidase expression compared with negative control (DMSO).

Then $1.0 \times 10^{-5} \mathrm{~mol} / \mathrm{L}$ 4-OHT, which inhibited about $20 \% \mathrm{ERR} \gamma$ constitutive activity at this concentration, was chosen as standard inverse agonist to test the inhibitory effect of test compounds on the inverse agonist activity of 4-OHT (Li et al., 2008b). The result showed that 4-OHT's activity was suppressed by 2,4-DCP, 3,4DCP, PCP, BPA and TBBPA (Fig. 4B) in a concentration dependent manner. Especially for 2,4-DCP, PCP and BPA almost all activity induced by 4 -OHT was reversed by co-administrated with these chemicals. The activity induced by TCBPA was so weak that the significant difference with control (DMSO) only be found at high concentration $\left(1.0 \times 10^{-6} \mathrm{~mol} / \mathrm{L}\right)$. In comparison, 2- $t$-butylphenol, 4- $t$ $\mathrm{OP}, 4$-phenylphenol and 2-isopropylphenol did not reverse the inverse agonist activity of 4-OHT.

ERR shares a high amino acid sequence homology with ER. Considering the fact that ERR can bind to several functional EREs, attempts were made to search for ant/agonists of ERR. In the present study, 4-t-OP and PCP were found to be strong inverse agonists for ERR $\gamma$. In the previous work, the compounds, toxaphene and chlordane, have been reported to behave as antagonists of ERR $\alpha-1$ and modulate estrogen biosynthesis (Yang and Chen, 1999). Meanwhile, the PCP and other compounds, 2,4-DCP, 3,4DCP, BPA and TBBPA, could interact with ERR $\gamma$ and showed a strong effect on the inverse agonist activity of 4-OHT. An interesting phenomena was found that PCP was proved as both ERR $\gamma$ inverse agonist and inhibitor of inverse agonist induced by 4-OHT in this study. In combination, PCP and 4-OHT might be substantially less toxic than either drug alone. Their combined toxicity may be due to independent effects of each compound, which is need for further investigate. Previous work had been shown that BPA could antagonize the inhibition activity of 4-OHT and such potential functional cross-talk between the ERR $\gamma$ and ER systems might used to explain some of the estrogenic activities of BPA (Takayanagi et al., 2006). Thus, similar to BPA, the interaction with the ERR $\gamma$ was a possible mechanism for the estrogenic activity for these compounds, including 2,4-DCP, 3,4-DCP, PCP, BPA, TBBPA and TCBPA.

\subsection{Action sites}

The results in this study suggested that the tested alkylphenols, including 2-tert-butylphenol, 4-t-OP and 2-isopropylphenol, mainly acted with AR, PR and/or ERR $\gamma$. 4-t-OP was the only chemical which exhibited both of ER $\alpha$ agonistic and antagonistic activity. Some xenoestrogens showing both ER agonistic and antagonistic effects had been reported, which also were confirmed that the antagonistic activity of these compounds, although statistically significant, was biologically marginal (Soto et al., 1997). In an in vivo test, the vitellogenin was detected in serum of the male medaka fish exposed to 4-t-OP in all treatment group in steadily increasing concentrations (Gronen et al., 1999), proving the estrogenic activity of $4-t-O P$ in fish. Endocrine disrupters are widely known for their estrogenic and androgenic effects by binding to ER or AR. But, the mechanisms of action of endocrine disrupters are actually complicated. For 4-t-OP, it was found that the obvious interrupting effect was inhibiting the gene expression via the PR at $1.0 \times 10^{-6} \mathrm{~mol} / \mathrm{L}$. Interestingly, similar results obtained with 2-tert-butylphenol and 2-isopropylphenol which may interact with PR showing strong anti-progesteronic activity. Therefore, although disruption of the progesterone activity was rarely addressed in the past, in contrast to estrogenic and anti-androgenic activities, it could well contribute to trigger a wide range of hormonal and/or anti-hormonal effect in vivo (Molina-Molina et al., 2006).
For BPA, TBBPA and TCBPA, they acted as ER $\alpha$ agonists as well as $A R$ and/or PR antagonists, but the abilities to interact with $E R \alpha, A R$ and PR were significantly different. TBBPA and TCBPA exhibited obvious estrogenic activity at $1.0 \times 10^{-5} \mathrm{~mol} / \mathrm{L}$, the highest concentration without cytotoxicity in our studies. However, the lowest concentration to observe the anti-progesteronic activities of TBBPA and TCBPA were detected at $1.0 \times 10^{-8} \mathrm{~mol} / \mathrm{L}$. Although anti-progesteronic activity of BPA was not found, BPA showed significant AR antagonistic activity with RIC20 values of $1.2 \times 10^{-6} \mathrm{~mol} / \mathrm{L}$. Moreover, we confirmed that all tested bispheols were also inhibitors that reversed the antagonistic effect induced by 4-OHT at the level of ERR $\gamma$, which can be used to explain the estrogenic activity of these compounds (Takayanagi et al., 2006).

In the present study, some chlorinated phenols and phenylphenol were also detected. The results showed that these phenols acted with more than one receptor. Taken together, all of the results suggest that the tested chemicals might exhibit multiple hormonal activities, which renders difficult interpretation of their mechanism of action. Although the potency of these phenols to behave as a hormone agonists or antagonists is low compared to the natural ligands, their ability to act via more than one mechanism might contribute to their biological effects in the intact organism, because the final response will likely be determined by the interactions of all the implicated pathways (Molina-Molina et al., 2006). Thus, for a detailed risk assessment of phenols concerning endocrine disruption in humans and animals, more data, especially in vivo data, are needed.

\section{Acknowledgements}

This study was supported by National Natural Science Foundation of China (20677075), the National Basic Research Program of China (2003CB415005), and Natural Science Foundation of Beijing Municipality (8061004).

\section{References}

Dhooge, W., Arijs, K., D’Haese, I., Stuyvaert, S., Versonnen, B., Janssen, C., Verstraete, W., Comhaire, F., 2006. Experimental parameters affecting sensitivity and specificity of a yeast assay for estrogenic compounds: results of an interlaboratory validation exercise. Anal. Bioanal. Chem. 386, 1419-1428.

Gaido, K.W., Leonard, L.S., Lovell, S., Gould, J.C., Babai, D., Portier, C.J., 1997. Evaluation of chemicals with endocrine modulating activity in a yeast-based steroid hormone receptor gene transcription assay. Toxicol. Appl. Pharmacol. 143, 205-212.

Graham, J.D., Clarke, C.L., 1997. Physiological action of progesterone in target tissues. Endocr. Rev. 18, 502-519.

Gronen, S., Denslow, N., Manning, S., Barnes, S., Barnes, D., Brouwer, M., 1999. Serum vitellogenin levels and reproductive impairment of male Japanese Medaka (Oryzias latipes) exposed to 4-tert-octylphenol. Environ. Health Perspect. 107 385-390.

Horard, B., Vanacker, J.M., 2003. Estrogen receptor-related receptors: orphan receptors desperately seeking a ligand. J. Mol. Endocrinol. 31, 349-357.

Jung, J., Ishida, K., Nishihara, T., 2004. Anti-estrogenic activity of fifty chemicals evaluated by in vitro assays. Life Sci. 74, 3065-3074.

Kim, H.J., Park, Y.I., Dong, M.S., 2005. Effects of 2,4-D and DCP on the DHTinduced androgenic action in human prostate cancer cells. Toxicol. Sci. 88, 52-59.

Kiparissis, Y., Metcalfe, T.L., Balch, G.C., Metcalfe, C.D., 2003. Effects of antiandrogens, vinclozolin and cyproterone acetate on gonadal development in the Japanese medaka (Oryzias latipes). Aquat. Toxicol. 63, 391-403.

Kitamura, S., Suzuki, T., Sanoh, S., Kohta, R., Jinno, N., Sugihara, K., Yoshihara, S. Fujimoto, N., Watanabe, H., Ohta, S., 2005. Comparative study of the endocrinedisrupting activity of bisphenol a and 19 related compounds. Toxicol. Sci. 84, 249-259.

Klotz, D.M., Ladlie, B.L., Vonier, P.M., McLachlan, J.A., Arnold, S.F., 1997. o,p'-DDT and its metabolites inhibit progesterone-dependent responses in yeast and human cells. Mol. Cell Endocrinol. 129, 63-71.

Kraus, W.L., Weis, K.E., Katzenellenbogen, B.S., 1995. Inhibitory cross-talk between steroid hormone receptors: differential targeting of estrogen receptor in the repression of its transcriptional activity by agonist- and antagonist-occupied progestin receptors. Mol. Cell Biol. 15, 1847-1857.

Kristensen, T., Baatrup, E., Bayley, M., 2006. p,p'-DDE fails to reduce the competitive reproductive fitness in Nigerian male guppies. Ecotox. Environ. Safe. 63, 148157. 
Lee, H.J., Chattopadhyay, S., Gong, E.Y., Ahn, R.S., Lee, K., 2003. Antiandrogenic effects of bisphenol A and nonylphenol on the function of androgen receptor. Toxicol. Sci. 75, 40-46.

Li, J., Ma, M., Rao, K.F., Wang, Z.J., 2008a. Construction the recombinant human estrogen receptor (hER) gene yeast using two-hybrid yeast technique. Asian J. Ecotoxicol. 3, 21-26.

Li, J., Ma, M., Giesy, J.P., Wang, Z.J., 2008b. In vitro profiling of the endocrine disrupting potency of organochlorine pesticides. Toxicol. Lett. 183, 65-71.

Ma, M., Li, J., Wang, Z., 2005. Assessing the detoxication efficiencies of wastewater treatment processes using a battery of bioassays/biomarkers. Arch. Environ. Contam. Toxicol. 49, 480-487.

Meisel, R.L., Sachs, B.D., 1994. The physiology of male sexual behavior. In: Knobil, E., Neill, J. (Eds.), The Physiology of Reproduction, second ed. Raven Press, New York, pp. 3-105.

Molina-Molina, J.M., Hillenweck, A., Jouanin, I., Zalko, D., Cravedi, J.P., Fernández M.F., Pillon, A., Nicolas, J.C., Olea, N., Balaguer, P., 2006. Steroid receptor profiling of vinclozolin and its primary metabolites. Toxicol. Appl. Pharm. 216, 44-54.

Nishihara, T., Nishikawa, J., Kanayama, T., Dakeyama, F., Saito, K., Imagawa, M. Takatori, S., Kitagawa, Y., Hori, S., Utsumic, H., 2000. Estrogenic activities of 517 chemicals by yeast two-hybrid assay. J. Health Sci. 46, 282-296.

Nuclear Receptors Nomenclature Committee, 1999. A unified nomenclature system for the nuclear receptor superfamily. Cell 97, 161-163.

Paris, F., Balaguer, P., Terouanne, B., Servant, N., Lacoste, C., Cravedi, J.P., Nicolas, J.C. Sultan, C., 2002. Phenylphenols, biphenols, bisphenol-A and 4-tert-octylphenol exhibit [alpha] and [beta] estrogen activities and antiandrogen activity in reporter cell lines. Mol. Cell. Endocrinol. 193, 43-49.

Rehmann, R.K., Schramm, K.W., Kettrup, A.A., 1999. Applicability of a yeast oestrogen screen for the detection of oestrogen-like activities in environmental samples. Chemosphere 38, 3303-3312.

Sohoni, P., Sumpter, J.P., 1998. Several environmental oestrogens are also antiandrogens. J. Endocrinol. 158, 327-339.

Sonnenschein, C., Soto, A.M., 1998. An updated review of environmental estrogen and androgen mimics and antagonists. J. Steroid Biochem. Mol. Biol. 65, 143-150.

Soto, A.M., Fernandez, M.F., Luizzi, M.F., Karasko, A.S.O., Sonnenschein, C., 1997. Developing a marker of exposure to xenoestrogen mixtures in human serum. Environ. Health Persp. 105, 647-654.
Sumpter, J.P., 2005. Endocrine disrupters in the aquatic environment: an overview. Acta Hydrochim. Hydrobiol. 33, 9-16.

Sun, H., Xu, L.C., Chen, J.F., Song, L., Wang, X.R., 2006. Effect of bisphenol A, tetrachlorobisphenol A and pentachlorophenol on the transcriptional activities of androgen receptor-mediated reporter gene. Food Chem. Toxicol. 44, 19161921.

Suzuki, T., Nakagawa, Y., Takano, I., Yaguchi, K., Yasuda, K., 2004. Environmental fate of bisphenol A and its biological metabolites in river water and their xenoestrogenic activity. Environ. Sci. Technol. 38, 2389-2396.

Takayanagi, S., Tokunaga, T., Liu, X., Okada, H., Matsushima, A., Shimohigashi, Y., 2006. Endocrine disruptor bisphenol A strongly binds to human estrogenrelated receptor $\gamma(\mathrm{ERR} \gamma)$ with high constitutive activity. Toxicol. Lett. 167, 95105

Tamura, H., Ishimoto, Y., Fujikawa, T., Aoyama, H., Yoshikawa, H., Akamatsu, M., 2006. Structural basis for androgen receptor agonists and antagonists: interaction of SPEED 98-listed chemicals and related compounds with the androgen receptor based on an in vitro reporter gene assay and 3D-QSAR. Bioorgan. Med. Chem. 14, 7160-7174.

Terasaka, S., Inoue, A., Tanji, M., Kiyama, R. 2006. Expression profiling of estrogenresponsive genes in breast cancer cells treated with alkylphenols, chlorinated phenols, parabens, or bis- and benzoylphenols for evaluation of estrogenic activity. Toxicol. Lett. 163, 130-141.

Tran, D.Q., Klotz, D.M., Ladlie, B.L., Ide, C.F., McLachlan, J.A., Arnold, S.F., 1996. Inhibition of progesterone receptor activity in yeast by synthetic chemicals. Biochem. Bioph. Res. Commun. 229, 518-523.

Wang, J., Xie, P., Kettrup, A., Schramm, K.W., 2005. Inhibition of progesterone receptor activity in recombinant yeast by soot from fossil fuel combustion emissions and air particulate materials. Sci. Total Environ. 349, 120128.

Xu, L.C., Sun, H., Chen, J.F., Bian, Q., Qian, J., Song, L., Wang, X.R., 2005. Evaluation of androgen receptor transcriptional activities of bisphenol A, octylphenol and nonylphenol in vitro. Toxicology 216, 197-203.

Yang, C., Chen, S., 1999. Two organochlorine pesticides, toxaphene and chlordane, are antagonists for estrogen-related receptor alpha-1 orphan receptor. Cancer Res. 59, 4519-4524. 